\title{
Linfoma Nasossinusal de Células T Natural Killer: Relato de Caso
}

\section{Nasosinusal Lymphoma of T Natural Killer Cells: Case Report}

\author{
Victor Labres da Silva Castro*, João Batista Ferreira**, Valeriana de Castro Guimarães***, \\ Gustavo Vasconcelos Nery****, Tiago Fernando Côrrea Aires*****, Wilder Alves****.
}

\author{
* Médico Residente de Otorrinolaringologia \\ ** Pós-Doutorado em Otorrinolaringologia.Professor Adjunto do Departamento de Cirurgia da Faculdade de Medicina - UFG. Chefe da Clínica de Otorrinolaringologia \\ do Hospital das Clínicas - UFG \\ *** Doutoranda em Ciência da Saúde UFG. Fonoaudióloga do Hospital das Clínicas - UFG \\ **** Médico Otorrinolaringologista do Hospital das Clínicas - UFG \\ ****** Médico Residente em Otorrinolaringologia do Hospital das Clínicas - UFG \\ Instituição: Hospital das Clínicas da Universidade Federal de Goiás. \\ Goiânia / GO - Brasil. \\ Endereço para correspondência: Victor Labres da Silva Castro - Hospital das Clínicas da Universidade Federal do Goiás - Primeira Avenida, s/n - Setor Leste Universitário \\ - Goiânia / GO - Brasil - CEP: 74605-020 - E-mail: vlabres@ hotmail.com \\ Artigo recebido em 16 de Junho de 2009. Artigo aprovado em 12 de Julho de 2009.
}

\section{RESUMO}

Introdução:

Objetivo:

Relato do Caso:

Comentários Finais:

Palavras-chave:

\section{SUMMARY}

Introduction:

Objective:

Case Report:

Final Comments:

Keywords:
O linfoma nasal primário é um tumor extranodal raro e representa $0,44 \%$ de todos os linfomas extranodais nessa localização. O linfoma nasal primário deriva da linhagem $\mathrm{T}$ em torno de $75 \%$ dos casos. Descrever um caso de Linfoma nasossinusal de células T Natural Killer, atendido no Hospital das Clínicas da Universidade Federal de Goiás.

Paciente de 48 anos, sexo feminino, apresentando tumefação difusa na hemiface esquerda, de consistência firme-elástica e dolorosa a compressão digital. Tomografia dos seios da face identificou um velamento maxilar total à esquerda e de algumas células etmoidais posteriores. Com a hipótese diagnóstica de uma afecção tumoral, optou-se por remoção cirúrgica via transmaxilar, sendo encaminhado o material para biopsia. O exame histopatológico diagnosticou um tumor altamente necrótico padrão angiocêntrico, população linfoide polimórfica e atípica (Linfoma T/NK), diante do diagnóstico a paciente foi submetida à quimioterapia com regressão total do edema facial.

O otorrinolaringologista deve estar atento para a existência dos linfomas entre as doenças nasossinusais, pois o diagnóstico precoce melhora a sobrevida na medida em que previne metástases, crescimento e destruição local.

linfoma extranodal de células T-NK, linfoma não Hodgkin, linfoma; linfoma de células T.

The primary nasal lymphoma is an uncommon extranodal tumor and represents $0.44 \%$ of all Extranodal lymphomas in this region. The primary nasal lymphoma derives from the T-lineage in nearly $75 \%$ of the cases.

To describe a case of nasosinusal lymphoma of T Natural Killer cells, attended in the Clinical Hospital of the Federal University of Goiás.

48-year-old female patient with diffuse tumefaction in the left hemiface of firm-elastic consistency and painful upon digital compression. Face sinuses tomography identified a total maxillary veiling to the left and some posterior ethmoidal cells. With the diagnostic hypothesis of a tumor affection, we opted for the surgical removal via a transmaxillary approach and the material was sent for biopsy. The histopathological exam diagnosed a highly necrotic tumor of angiocentric pattern, polymorphic and atypical lymphoid population ( $\mathrm{T} / \mathrm{NK}$ Lymphoma); with the prognosis, the patient was submitted to chemical therapy with total regression of the facial edema.

The otorhinolaryngologist must be attentive as regards the existence of lymphomas among the nasosinusal diseases, because the early diagnosis improves the survival as it prevents metastases, growth and local destruction.

T-NK cells extranodal lymphoma, non-Hodgkin lymphoma, lymphoma, cells lymphoma. 


\section{INTRODUÇÃO}

O linfoma nasal primárioé um tumor extranodal raro e representa $0,44 \%$ de todos os linfomas extranodais localizados nessa região. Dentre os tumores extranodais os linfomas não-Hodgkin são divididos em neoplasias de células B e T e linfomas de células T Natural Killer - T/NK, são frequentes nos países orientais, mas raros na população ocidental. Aproximadamente $75 \%$ dos casos de linfoma nasal primário derivam da linhagem $\mathrm{T}(1,2)$.

O fenótipo é determinado por imunoperoxidase com vários anticorpos monoclonais. A expressão do CD 56 (molécula de adesão celular neural, marcador celular Natural Killer) é incomum entre os linfomas, mas define o linfoma de células T/Natural Killer (3).

O linfoma de células T/NK pode se manifestar em qualquer faixa etária, com predominância no gênero masculino, sendo a idade avançada e tumor volumoso fatores associados à baixa sobrevida. Essa neoplasia pode disseminase para outros sítios extranodais, como a pele, tecido subcutâneo, trato gastrointestinal, testículos dentre outros $(2,4)$.

Neste artigo é proposto a apresentação de um caso, cuja relevância reside no fato deste se constituir em caso raro no ambulatório de otorrinolaringologia e em outras especialidades.

No presente relato os autores descrevem um caso de Linfoma nasossinusal de células T Natural Killer, atendido no Hospital das Clínicas da Universidade Federal de Goiás.

\section{Relato do Caso}

Paciente de 48 anos, sexo feminino, natural de Goiânia - Goiás procurou o Pronto Socorro de Otorrinolaringologia do Hospital das Clínicas da Universidade Federal de Goiás em novembro de 2007, com o seguinte quadro clínico: edema doloroso e progressivo na hemiface esquerda há um mês com rinorreia purulenta, sem melhora com uso de antibióticos. Relatava, ainda, leve emagrecimento e sudorese noturna desde o início da doença. Sem outros sintomas otorrinolaringológicos e locoregionais.

No momento da consulta, a paciente encontrava-se em bom estado geral com sinais vitais normais. Na inspeção e palpação cérvico-facial identificou-se presença de tumefação difusa na hemiface esquerda, de consistência firme-elástica e dolorosa a compressão digital. Sem alterações na região do pescoço (Figura 1).

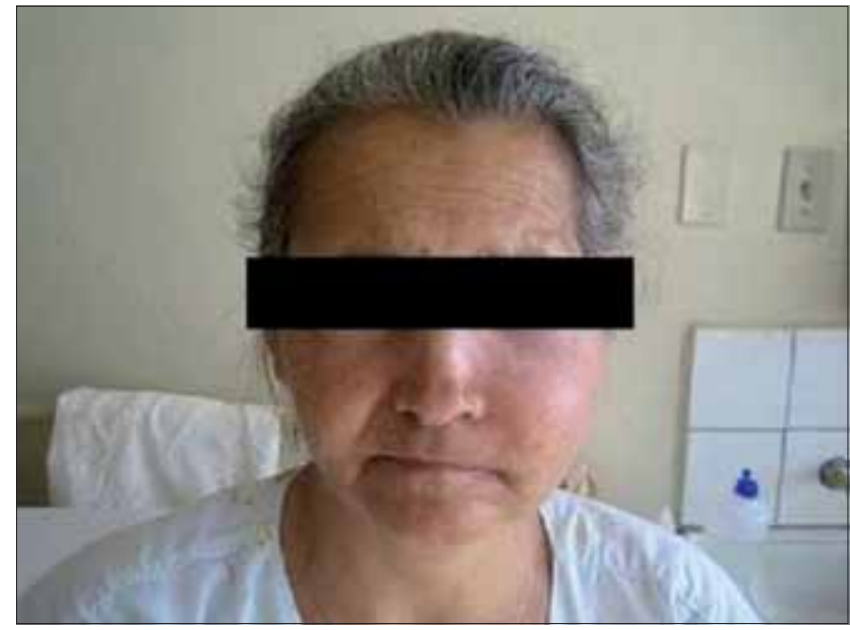

Figura 1. Edema de hemiface esquerda. Consistência firme e Ruborizada. HC/UFG 2007.

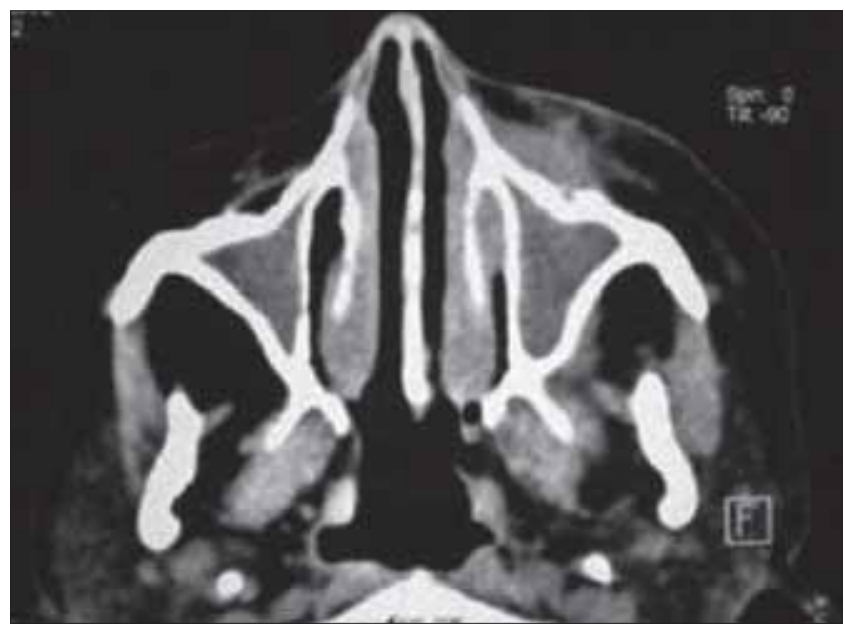

Figura 2. TC de seios da face. Corte axial em janela de partes moles evidencia presença de material com densidade de partes moles ocupando os seios maxilares. À esquerda ocorre extensão do processo pelas paredes anterior e medial do seio maxilar com pequeno borramento da gordura pré-maxilar. HC/UFG 2007.

$\mathrm{Na}$ avaliação clínica otorrinolaringológica a orofaringoscopia e otoscopia não apresentavam alterações. Na rinofaringoscopia anterior observou-se presença de secreção purulenta no meato médio esquerdo.

O exame de nasofaringolaringoscopia mostrou secreção no meato médio esquerdo com recobrimento de toda mucosa de aparência edemaciada e obstrutiva. Cavidade nasal direita não revelou alterações.

A tomografia computadorizada dos seios da face revelou velamento maxilar esquerdo total com comprometimento de células etmoidais posteriores (Figuras 2 e 3). 


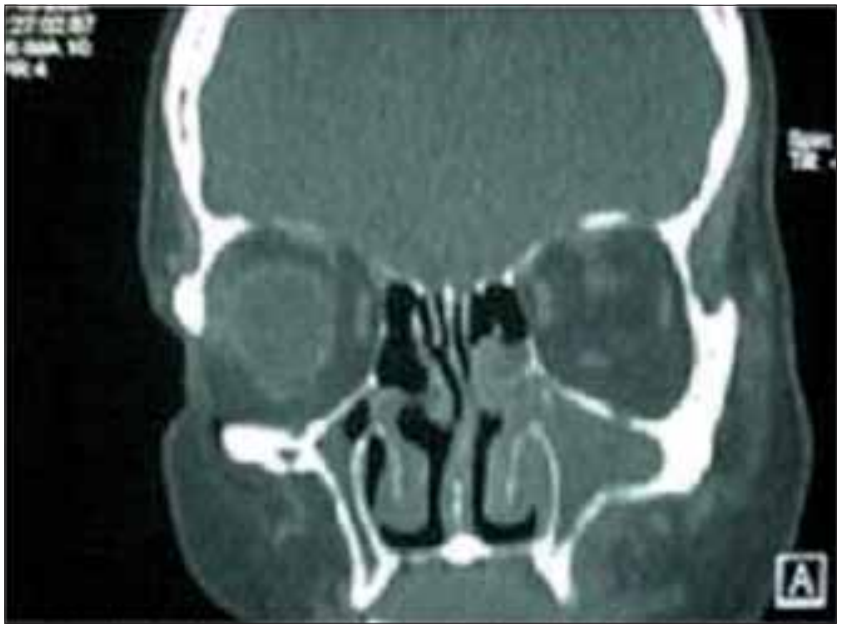

Figura 3. TC de seios da face. Corte coronal em janela óssea não mostra evidências de lesão óssea parietal. HC/UFG 2007.

Sugestivo de processo inflamatório (celulite) pré-maxilar à esquerda, com um aumento do volume da hemiface esquerda.

Diante do quadro clínico a paciente foi internada. Foram solicitados parecer da equipe de hematologia e exames laboratoriais como: hemograma, coagulograma, glicemia e creatinina, cujos resultados mostraram-se normais e sorologia anti-HIV 1 e 2 negativas na ocasião.

Com hipótese diagnóstica de lesão tumoral com origem no seio maxilar esquerdo optou-se pela biopsia incisional através da abordagem cirúrgica via transmaxilar para obter fragmentos da massa e posterior análise anatomopatológica.

O exame histopatológico diagnosticou um tumor altamente necrótico padrão angiocêntrico, população linfoide polimórfica e atípica (Linfoma T/NK). Marcadores: $\mathrm{CD} 3+, \mathrm{CD} 30+, \mathrm{CD} 5+, \mathrm{EBV}-, \mathrm{CD} 56+, \mathrm{CD} 43-, \mathrm{ALC}+, \mathrm{AE} 1 \mathrm{AE} 3-$ , CD45Re+, CD20-.

A tomografia computadorizada de tórax e abdome total encontrava-se sem alterações. A biópsia de medula óssea mostrou-se normocelular para a idade taxa de ocupação da mesma de 50\%.

Com o diagnóstico de linfoma de células NK do seio maxilar esquerdo e ausência de metástase iniciou-se o tratamento quimioterápico com regressão total do edema facial e melhora acentuada do quadro. Durante o seguimento por um ano, houve manutenção da melhora clínica.

Considerando o processo recidivante, a paciente permanece em acompanhamento com as equipes de otorrinolaringologia e hematologia do hospital, para seguimento ao tratamento.

\section{DISCUSSÃO}

O interesse na descrição deste caso é evidenciado na raridade com que a doença ocorre, assim como o desenrolar e desfecho do mesmo.

No caso descrito, a paciente apresentou comprometimento da hemiface esquerda e seios paranasais. A literatura descreve que o trato gastrointestinalé o local mais comum de surgimento do linfoma extranodal, seguido da região da cabeça e o pescoço. Nesta região, os locais mais afetados são nasofaringe, tonsilas e base da língua. Outras estruturas como os seios paranasais, órbita e as glândulas salivares, podem ser afetadas. Entretanto, o envolvimento da cavidade oral é incomum $(5,6,7)$.

O Linfoma não-Hodgkin acomete frequentemente adultos com idade entre 40 e 80 anos. Há uma nítida relação de incidência entre linfoma não-Hodgkin e jovens com sorologia HIV positiva. Indivíduos HIV positivos apresentam 60 vezes mais riscos que a população geral. Estudos mostram que 3\% das pessoas infectadas com HIV desenvolvem linfomas $(8,9)$. Contrariamente no caso apresentado houve sorologia Elisa negativa para HIV 1 e 2

O diagnóstico da neoplasia nasossinusal é muitas vezes tardio, devido a sua possível manifestação oligossintomática, pouco a parente. Manifestações clínicas como: dor facial, edema, epistaxe, secreção purulenta, dor odontogênica, obstrução nasal, sinusite, fístulas sinusocutâneas, necrose, ulceração e perfuração septal, entre outras podem estar presentes e, por vezes, acompanhados de febre e perda de peso $(2,3)$. No caso relatado houve edema facial ruborizado, sudorese noturna, rinorreia purulenta e emagrecimento. O quadro clínico desenvolvido pela paciente está condizente com relatos da literatura, sugerindo o diagnóstico da doença.

O CD-56 é um marcador específico para o linfócito Natural Killer, e o linfoma T/NK constitui uma nova terminologia para uma série de epônimos que nomeavam esta doença previamente. Este linfoma proporciona um prognóstico reservado, sendo a estatística de sobrevida conflitante de $9 \%$ em três anos até 46 a $63 \%$ em cinco anos (10). Este marcador esteve presente no estudo imunohistoquímico do material removido no seio maxilar da paciente.

\section{COMENTÁRIOS FINAIS}

O otorrinolaringologista deve estar atento para a existência dos linfomas entre as doenças nasossinusais $\mathrm{O}$ linfoma nasossinusal de células T/NKé linfoma extranodal 
incomum, no entanto deve ser considerado no diagnóstico diferencial dos tumores dessa região.

A atuação conjunta com o hematologista e importante no tratamento e condução dessa doença, pois é necessária a intervenção quimioterápica.

O profissional deve estar alerta, diante de quadros inespecíficos e arrastados, uma vez que, a identificação e o diagnóstico precoce melhoram a sobrevida na medida em que previne metástases, crescimento e destruição local.

\section{REFERÊNCIAS BIBLIOGRÁFICAS}

1. Feng YF, Wu QL, Zong YS. Correlation of immunophenotype of sinonasal non-Hodgkin's lymphoma to Epstein-Barr virus infection. Ai Zheng. 2007, 26:1170-6.

2. Abrahão M, Cervante O, Alvarenga EHL. Tumores da cavidade nasal e da orofaringe. In: Costa SS, Cruz OLM, Oliveira JAA. Otorrinolaringologia: princípios e Prática. $2^{\text {a }}$ ed. São Paulo: Artmed; 2006 pp. 720-34.

3. Castro M, Silveira E, Figueiredo M, Ribeiro C. Linfoma Nasossinusal de Célula T/NK - Relato de Caso. Rev Bras Otorrinolaringol. 2001, 2761:67-2.
4. Sankaranarayanan S, Chandrasekar T, Srinivasa Rao P, Rooban T, Ranganathan K. Maxillary Non-Hodkins Lymphoma. JOMFP. 2005, 9:1:34-36.

5. Fukuda Y, Ishida T, Fujimoto M, Veda T, Aocasa K. Malignant lymphoma of the oral cavity: clinicopathologic analysis of 20 cases. J Maxillo Fac Surg. 1985, 13:85-92.

6. William HW, Stephen GH, Peter MB. Lymphoma of the Nose and Paranasal Sinuses. Arch. Otolaryngol. 1983, 109:104-7.

7. Richard PR. Beware of malignant lymphoma masquerading as facial inflammatory processes. Oral. Surg. Oral. Med. Oral. Pathol. 1991, 71:415-9.

8. Landa LS, Perez NBI, Montes GE, Ereno ZC, Pereda ME, BarbierHL, Garaizar ZJ, Santamaria SJ. Maxillary non hodgkins lymphoma. A report of two clinical cases and review of the literature. Medicine Oral. 1998, 3(5):299-308.

9. Robbins KT, et al. Primary lymphomas of the nasal cavity and paranasal sinuses. Cancer. 1985, 56:814-19.

10. Siu LL, ChanJK, Kwong YL. Natural killer cell malignances: Clinicopathologic and molecular features. Histol. Histopathol. 2002, 17:554. 